\title{
What influences patient decision-making in amyotrophic lateral sclerosis multidisciplinary care? A study of patient perspectives
}

This article was published in the following Dove Press journal:

Patient Preference and Adherence

26 November 2012

Number of times this article has been viewed

\author{
Anne Hogden' \\ David Greenfield' \\ Peter Nugus' \\ Matthew C Kiernan ${ }^{2}$ \\ 'Centre for Clinical Governance \\ Research, Australian Institute of \\ Health Innovation, University of \\ New South Wales, ${ }^{2}$ Prince of Wales \\ Clinical School, University of New \\ South Wales, and Neuroscience \\ Research Australia, Sydney, New \\ South Wales, Australia
}

Background: Patients with amyotrophic lateral sclerosis (ALS) are required to make decisions concerning quality of life and symptom management over the course of their disease. Clinicians perceive that patients' ability to engage in timely decision-making is extremely challenging. However, we lack patient perspectives on this issue. This study aimed to explore patient experiences of ALS, and to identify factors influencing their decision-making in the specialized multidisciplinary care of ALS.

Methods: An exploratory study was conducted. Fourteen patients from two specialized ALS multidisciplinary clinics participated in semistructured interviews that were audio recorded and transcribed. Data were analyzed for emergent themes.

Results: Decision-making was influenced by three levels of factors, ie, structural, interactional, and personal. The structural factor was the decision-making environment of specialized multidisciplinary ALS clinics, which supported decision-making by providing patients with disease-specific information and specialized care planning. Interactional factors were the patient experiences of ALS, including patients' reaction to the diagnosis, response to deterioration, and engagement with the multidisciplinary ALS team. Personal factors were patients' personal philosophies, including their outlook on life, perceptions of control, and planning for the future. Patient approaches to decision-making reflected a focus on the present, rather than anticipating future progression of the disease and potential care needs.

Conclusion: Decision-making for symptom management and quality of life in ALS care is enhanced when the patient's personal philosophy is supported by collaborative relationships between the patient and the multidisciplinary ALS team. Patients valued the support provided by the multidisciplinary team; however, their focus on living in the present diverged from the efforts of health professionals to prepare patients and their carers for the future. The challenge facing health professionals is how best to engage each patient in decision-making for their future needs, to bridge this gap.

Keywords: consumer perspectives, patient decision-making, multidisciplinary care, amyotrophic lateral sclerosis

\section{Introduction}

Amyotrophic lateral sclerosis (ALS), also known as motor neurone disease, is a terminal and progressive multisystem disorder ${ }^{1,2}$ without a cure. Treatment is based on symptom management and enhancement of patients' quality of life as they confront changes in physical, cognitive, and behavioral function. ${ }^{3}$ Disease survival time is short, typically 2-3 years on average. Consequently, complex ethical and cultural issues surround patient choices for neurorehabilitation and palliative care. ${ }^{4-6}$ Against this background, patients make many decisions concerning symptom management and quality of life
Correspondence: Anne Vaughan Hogden Centre for Clinical Governance Research, Australian Institute of Health Innovation, Faculty of Medicine, Level I, AGSM Building, University of New South Wales, Sydney NSW 2052, Australia

$\mathrm{Tel}+6 / 29385307 \mid$

Fax +6I296634926

Email a.hogden@student.unsw.edu.au 
throughout the course of the disease. Decisions may include choices between invasive and noninvasive ventilation, ${ }^{7-9}$ insertion of gastrostomy to facilitate adequate nutrition and hydration, ${ }^{10,11}$ choices of mobility and communication equipment as independence decreases, ${ }^{12,13}$ completion of advance care plans anticipating future needs, ${ }^{14}$ involvement with home-based or inpatient palliative care services, ${ }^{15}$ and preferences for end-of-life care. ${ }^{16,17}$

The health care and psychosocial complexities of living with a fatal condition create a dynamic and challenging environment for decision-making. ${ }^{18,19}$ Patient-centered decision-making relies on patients receiving sufficient information about their condition and the treatment options available to them, having the opportunity to discuss these options with their health practitioner, and retaining control over the implementation of the decision. ${ }^{20}$ A review of patient decision-making in palliative care found that patients rarely achieve their desired level of involvement due to information gaps and tendencies to delay their treatment decisions. ${ }^{21}$ Barriers to end-of-life discussions stem from patientrelated, health professional and organizational constraints. ${ }^{22}$ Decision-making research in ALS care focuses on factors influencing specific health care choices, particularly in end-of-life care. ${ }^{7,17,23}$ Patient perceptions of autonomy, ${ }^{24-26}$ attachment to life, ${ }^{11}$ expectations of improved quality of life, ${ }^{27}$ and family burden ${ }^{28}$ impact on their choices. Patients use an iterative and cyclical decision process as they negotiate change, ${ }^{29}$ and adopt a "wait and see" approach towards symptom management and quality of life decisions. ${ }^{30}$ ALS patients' lack of engagement in decision-making in generalist health care environments has been attributed to inadequate information and service access. ${ }^{31}$

Patient experiences are an important resource for improving multidisciplinary ALS care. Large-scale studies have examined patient decision-making in ALS, investigating the types of decisions patients make, ${ }^{11}$ the timing of their decisions, ${ }^{15}$ their preferences for clinician and family involvement, ${ }^{25}$ and patients' eventual fidelity to their earlier choices. ${ }^{11}$ These studies have demonstrated the complex choices patients face, but they lack the deeper perspective of the patient as decision-maker. Patient perspectives provide insight into patient-centered care from the viewpoint of service users, ${ }^{32-35}$ the challenges to patient engagement in care, ${ }^{36}$ and potential incongruity between patient and health professional expectations. ${ }^{33,34,37}$ Inclusion of consumer perspectives prevents the compartmentalization of influences on health care delivery, and accommodates the interplay of various levels of influences and their effects. Patient perspectives open the possibility of a more comprehensive account of the way decisions are made. This knowledge can inform clinical practice and guideline development to accommodate better the needs of patients.

Patient-clinician relationships have an influence on decision-making in patients with ALS. Health professionals facilitate patient decision-making by providing decisionspecific education, ${ }^{9,11,31}$ maintaining effective communication with patients and carers, ${ }^{17,24,26}$ and supporting patient autonomy. ${ }^{8}$ However, well-timed decision-making remains a challenge for health professionals and patients. ${ }^{17,37,38}$ Specialized multidisciplinary clinical ALS services have emerged to provide a supportive environment for collaborative and patient-centered care, ${ }^{39,40}$ yet the impact of specialized multidisciplinary ALS services on decision-making is unknown. ${ }^{41,42}$ Additionally, there has been no evaluation of the benefits that specialized clinics provide in terms of patient satisfaction $^{42}$ or patient-clinician relationships. Therefore, the aim of the present study was to investigate decision-making from the perspective of patients within specialized multidisciplinary clinical ALS services in an attempt to identify factors that influence decision-making for symptom management and quality of life.

\section{Materials and methods}

This research was conducted as an exploratory study, ${ }^{43}$ because we know little about decision-making from the perspective of consumers within specialized multidisciplinary clinical ALS services. An exploratory study was necessary because the topic requires engagement and discussions with patients in a confronting situation. The qualitative approach, and in particular, semistructured interviews with open-ended questions, provides the flexibility necessary to be respectful and responsive to each participant. This approach has been used in similar situations in palliative and ALS research when examining such issues. ${ }^{34,44}$

\section{Participants and setting}

Participants were recruited for the study by use of convenience sampling. ${ }^{45}$ Patients attending two specialized multidisciplinary ALS clinics were invited to participate in the study. One clinic was based in a metropolitan center and the other in a regional area. Both clinics offered a comprehensive range of services to patients from south-eastern Australia. Services included neurology, allied health, and palliative care services, linked to gastroenterology and respiratory services, and the ALS Association. Thirty patients were approached while attending the clinics, and given an information sheet outlining 
the project. Those who indicated interest in the study were contacted by email. Fourteen participants were recruited (47\% response rate, Table 1). Participants attended scheduled 3-monthly appointments at the clinics, and many (57\%) attended with a family member. ALSFRS-R (Amyotrophic Lateral Sclerosis Functional Rating Scale-Revised $)^{46}$ scores were taken to indicate participants' physical status. Half of the participants were independently mobile. Ten participants (71\%) used verbal communication, and four used an electronic device (tablet or laptop) or handwriting as assistive or alternative communication strategies during the interview. The majority of respondents lived at home, while one person lived in a residential care facility. Eleven participants (79\%) lived with a spouse or family member, and four continued to work at the time of interview. A diverse participant group resulted, reflecting the heterogeneous nature of ALS symptoms and patterns of disease progression.

\section{Data collection and analysis}

An interview guide (Table 2) was developed from the decision-making literature..$^{20,47-49}$ The guide was evaluated and refined in consultation with two expert clinicians and researchers experienced in multidisciplinary ALS care. Sixteen open-ended questions resulted. The questions targeted participant experiences with specialized multidisciplinary clinical ALS services, participants' decision-making activity, and improvements in decision-making in multidisciplinary clinical care. Written consent was obtained from each participant prior to interview. Human research ethics approvals were provided by the University of New South Wales and participating health services.

Data collection took place between May 2011 and May 2012. Eleven participants took part in face-to-face interviews, while two respondents elected to be interviewed by phone. Interviews lasted up to 30 minutes. The remaining participant answered questions by email. Interviews were audio recorded and transcribed, and then member-checked. Each participant

Table I Participant demographics

\begin{tabular}{ll}
\hline Participant characteristics & Parameter \\
\hline Age at interview (years) & Mean 60.5 (range 40-77) \\
Time from diagnosis to interview (months) & Mean 32.07 (range 2-93) \\
ALSFRS-R score & Mean 35.3 (range 22-47) \\
(0, minimal physical function; 48, full & \\
physical function) & \\
Gender & Male, 7 (50\%) \\
& Female, $7(50 \%)$ \\
\hline
\end{tabular}

Abbreviation: ALSFRS-R, Amyotrophic Lateral Sclerosis Functional Rating ScaleRevised.
Table 2 Interview themes and questions

\begin{tabular}{ll}
\hline Theme & Question \\
\hline Experience with & AI. Can you tell me about receiving your \\
multidisciplinary care & diagnosis of ALS? \\
BI. How did you access ALS services and \\
information? \\
Decision-making & CI. What decisions have you had to make \\
activity & C2. Whince your diagnosis? \\
& decisions to you? \\
DI. How did you make your decisions? & D2. Who did you involve? \\
D3. Who had the final say in your decisions? & D4. Has this changed since your diagnosis? \\
EI. What things do you feel you have \\
control over? What things do you not? \\
FI. How capable have you felt to make \\
your decisions? \\
F2. Have you ever wanted someone to \\
make them on your behalf? \\
Choose one health care decision: \\
GI. What help have you had to make this \\
decision? \\
G2. What information did you receive \\
about this treatment? \\
G3. How did this information influence your \\
decision? \\
H2. What do you feel influenced your \\
decisions? \\
II. How could services for people with \\
ALS be improved?
\end{tabular}

Abbreviation: ALS, amyotrophic lateral sclerosis.

was given a copy of their transcript to ensure they had been accurately checked. The endorsed transcripts were prepared for analysis by importing them into QSR NVIVO 9 software (QSR International Pty Ltd, Melbourne, Australia). Data were pooled across the two sites because of the small number of sites and participants. The analysis was conducted by one author $(\mathrm{AH})$ and then cross-checked by two coauthors (DG, $\mathrm{PN})$ until agreement was reached.

The transcripts were systematically analyzed using a stepwise procedure of thematic analysis ${ }^{50}$ to identify patterns within the data and reveal trends and relationships between the views of the participants. ${ }^{51}$ Significant participant statements were first selected for inclusion in the analysis. These excerpts characterized patient experiences and influences on decisionmaking. The selected statements were then assigned codes that summarized the meaning of the statement. Eighty-seven codes were identified from the participant statements. These codes were clustered together into meaning-related groups to create 12 subtheme categories. Each subtheme category was endorsed by between seven and 12 participants, and contained 13-40 statement references. Relationships between the 
subthemes were identified, refining the subtheme categories into three conceptual themes and six associated subthemes. ${ }^{51}$ Exemplary quotes were chosen from the participant statements to represent each theme.

\section{Results}

Structural, interactional, and personal factors were found to influence patient participation in decision-making. The structural factor was the decision-making environment of the specialized multidisciplinary ALS clinics. Interactional factors were patient experiences of ALS, comprising patient reactions to the diagnosis, their responses to deterioration, and engagement with the multidisciplinary ALS team. Personal factors were the patients' personal philosophies, and included their outlook on life, their perception of control, and their planning for the future.

\section{Structural factor: decision-making environment}

Multidisciplinary clinical ALS services offered a supportive decision-making environment by providing patients and families with disease-specific information, specialized symptom management and care planning, and the opportunity for discussion of treatment options. Participants reported confidence in the ALS teams because of their expertise, specialized knowledge, and dedicated ALS service. Representatives from the ALS Association attended both clinics to provide support and information to patients and families. Patients were offered detailed, and where available, research-based information on which to base their decisions. This included a range of print-based and Internet resources on the nature and progression of ALS, and the available clinical and support services to assist with symptom management. Clinic appointments were scheduled at 3-monthly intervals to promote regular discussion of patients' current health care and psychosocial issues, and to plan for anticipated care needs. Participants viewed the multidisciplinary team as the main source of assistance outside of the physical, emotional, and financial support provided by family. The supportive decision-making environment underpinned patient experiences of specialized ALS services.

\section{Interactional factors: patient experiences of ALS}

Three key experiences of ALS influenced patient engagement in decision-making. These were participants' reaction to the diagnosis, response to deterioration, and engagement with the multidisciplinary team.

\section{Reaction to the diagnosis}

Participants reported a common reaction of shock on receiving their diagnosis. Their responses became complex and nuanced as they came to understand the meaning of the diagnosis. Three people viewed the diagnosis as confirmation of their own conclusions.

"I was expecting it, it wasn't a surprise. I was pretty much even convinced before I went to see him that this is what I had. So after getting confirmation from the initial neurologist it was a bit of a weird drive home. Although you expect it and it is not a surprise, it is still a bit of a shock."

Two participants indicated little emotional reaction due to their limited understanding of the implications at the time of diagnosis. One patient diagnosed 2 months prior to interview experienced difficulty coming to terms with the condition and was distressed by the lack of an overt cause.

"Because I'm such a healthy person, and to get something

like this, you think 'OK, what did I do?' It's not right."

Several participants expressed frustration that health professionals were unable to inform them of their personal survival times and disease trajectories. However, those who had received the diagnosis over a year prior to interview demonstrated greater emotional adjustment to their condition.

"After they told me I suffered depression for about three months, and then after three months I said to myself, 'You'd better snap out of this'."

Once they had begun to come to terms with the diagnosis, two participants expressed a positive outlook, reframing the situation as an opportunity to make the most of the time they had left. Other participants acknowledged the difficulty of taking in medical information and the inevitable nature of their situation.

"It was a bit hard to take in, when I read what to expect from

a website, but that's what it was then, and so be it."

Participants demonstrated diverse reactions to the common experience of an ALS diagnosis. Their reaction to this experience influenced their readiness to learn about their condition and participate in specialized multidisciplinary ALS care and decision-making.

\section{Response to deterioration}

Participant responses to physical deterioration and loss of function were framed in terms of lifestyle changes, shifts in priorities, and adoption of coping strategies. Many patients 
reported practical adjustments to their lifestyle to retain their independence, including changes to home and workplace environments, and travel arrangements.

"You just adapt as necessary and move on ... I ordered groceries online when I could no longer get to the supermarket, rather than have to rely on friends."

Nevertheless, respondents also acknowledged increasing dependence on support from family and health care services. The majority of participants (86\%) stated the importance of their family relationships. Many had changed their priorities to maximize their time with family and some framed survival goals around their children's milestones.

"After I was told that diagnosis, and told I would be in a chair within 12 months, I decided to leave work. I didn't want to spend 12 months there and not be able to walk. And I wanted to spend more time with my family. My work wasn't that important to me."

Respondents' mechanisms for coping with the inevitability of their condition were expressed as denial, resilience, or a focus on maintaining current routines and lifestyle. These are exemplified in the following statements.

"To a large extent, I keep my head pretty well buried in the sand as far as the reality of all this is concerned. Because as soon as you lift your head up and start to think about all these things - you have to every now and then - it all gets a bit overwhelming."

"I'll keep going because I just won't lay down and die. Simple as that. But you just don't give up."

“That's what keeps us going I think. Our daily routine seems to be onerous on us to have to undergo, and I mean things like looking after the grandkids, and going out with friends and then running the gauntlet of clinic and doctors and rehabilitation, and all that sort of thing. But certainly we don't get a lot of time to think about the bad side."

Religion and spirituality did not feature strongly as a source of support or coping. Two participants identified religious beliefs, although they no longer attended church. The remaining participants described themselves as having no religious or spiritual beliefs. Regardless of the coping strategy they chose, respondents conveyed a common theme, ie, their decision-making was guided by a focus on the present, because that was preferable to thinking about the future. Maintaining current well-being was a higher priority than proactive engagement in decision-making for disease progression.

\section{Engagement with the multidisciplinary team}

The respondents' third key experience of ALS was their engagement with the multidisciplinary ALS team that resulted from enduring clinical relationships. Participants reported both positive and negative experiences with health care teams; however, the majority of negative health care experiences related to nonspecialized health services. These included extended waiting times for diagnosis, insensitive communication of the diagnosis by generalist neurologists, and communication breakdown between external health care service providers. One participant drew comparisons between cancer and ALS services, highlighting the impact of a terminal prognosis on engaging in health care decisions.

"Cancer is a walk in the park by comparison [to ALS]. There is something you can do for a start, and probably these days very few of them where you don't have some sort of fighting chance, some glimmer of hope. I don't actually know whether that is a good thing or not. There's part of me thinks that the inevitability of ALS means that you don't get caught up in all sorts of rigorous treatments and things like that, that make life miserable."

Participants expressed satisfaction with specialized multidisciplinary ALS care, and valued their relationships with the clinical ALS team. Beneficial aspects of their relationship with this team were three-fold: the specialized care, information, and support received through the clinics; trust in the health care team; and ease of communication with health professionals. Respondents acknowledged the importance of specialized services, their ongoing care, and regular communication with clinic staff.

"The level of care, information and everything has been outstanding."

Patients characterized their relationships with the clinic health professionals as important to their experience. They reported their development of trust and confidence in the team.

“Dr B, she was the first one I saw here, and it couldn't have gone better for me having seen her, because I'm a very closed person. And probably I wouldn't have seen you, except for what's gone before."

Participants relied on the team to provide services to meet their changing needs over time. They also saw the health professionals as a link to ALS research, to keep them informed of developments. 
"I felt if there was a way of stopping or slowing the disease

down, he would find it."

The process of engagement was enhanced by the clinic structure and organization of regularly scheduled appointments, in a familiar setting with the same clinical and administration staff. Patient engagement was further demonstrated by participants' previous research participation. The majority of respondents had taken part in research activities linked to their clinic, as a way of helping future patients.

Participants reported one particular challenge to attending the ALS clinic. Being face to face with other ALS patients at more advanced stages of the disease was a confronting experience which they dealt with each time they attended the clinic. Two respondents stated this had a negative impact on their coping ability, and they preferred to avoid other patients at the clinic.

"I don't like to see other people worse than me that I will become like."

Others described themselves as being "different" from the other patients. Participants acknowledged the difficulty of contemplating what the future held. Although reminded of the future when they engaged with the clinic team, patients found ways to separate themselves from other people with ALS to minimize their discomfort.

\section{Personal factors: patients' personal philosophies}

A central influence on patient approaches to decision-making for symptom management and quality of life was the personal philosophy each held. This issue was comprised of three parts, namely their outlook on life, their perception of control, and their planning for the future.

\section{Outlook on life}

Elements of participants' outlook on life overlapped with their reported coping strategies. Life views were expressed as maintaining a positive outlook, being resilient, and remaining engaged in normal life. These elements are reflected in the following statements.

“To start with, I've always been a glass half full type person.

I always look for the best in any situation ... But I must say though, I've never been a victim in my life. I'm not a victim of ALS, I have ALS."

"Determination to do what I can for as long as I can, desire for independence [and a] resilient temperament."
"I wanted everything to be just normal, as anything could happen to anyone or all of us at any time; one only has to watch the news."

One participant framed his outlook as an active avoidance of negative thoughts and experiences. He saw avoidance as a way to maintain his sense of well-being. In addition, family relationships emerged as a strong influence on shaping patients' outlook on life, and therefore on decisions for symptom management. Family provided reasons for living and motivated patients to choose interventions to prolong their lives, such as artificial feeding and hydration or to continue their employment.

"I know my family will think I'm nuts and talk me into it, so I am here longer with them ... I put the family in my mind first and think what they want, as we have discussed everything right from the beginning, before I changed too much.”

\section{Perceptions of control}

Perceptions of control were framed in terms of the control participants felt they held over their life, including their preservation of independence and the control they had over treatment choices. Respondents stated their intention to maintain control over their life for as long as possible, and this shaped their decisions for lifestyle changes.

"I'm fighting this issue very hard, to stay sane and everything else and that's why I want do what I'm doing ... I have a very good brain, and I don't want to lose that with everything. That's the reason behind what I'm doing."

Additionally, respondents specified a desire to have control over the circumstances of their death. This was associated with a wish to remove burden from their families.

"I think we should be able to have control, really. My dog will not suffer. I want the same. I'm very, very sure about how I feel about my death."

Despite increasing physical degeneration, the majority (78\%) reported maintaining control over their daily lives. None considered that ALS was in control of their lives.

"I don't have control over the rate of degeneration. I think I pretty much have reasonable control over everything else at this point. I don't think things are totally out of control. Although, the extent of which control can be applied in terms of, well there is no treatment, but management; I suppose I'm still calling the shots on that. Even if it's to 
the extent where I haven't done anything, it's still been with me effectively making that decision by not making a decision."

Several participants cited preservation of independence and autonomy as a motivating factor behind decisions. However, less than one third of respondents reported making decisions independently. Most patients (71\%) preferred to share the responsibility of decision-making with others, by drawing on family support or the expertise of health professionals. None reported wanting others to make decisions on their behalf.

\section{Planning the future}

Participants demonstrated paradoxical attitudes towards their future, revealed in their planning and information-seeking activity. Half of the respondents reported completing living wills or advance care directives. Nonetheless, under one third identified plans for their future care needs or the needs of their families. Several participants (28\%) reported reluctance to learn about the disease course, preferring family members to seek and interpret information on their behalf. A significant proportion (43\%) of respondents reported a "wait and see" approach, preferring to focus on their immediate concerns or daily routine rather than their future needs.

"I am still doing basically everything that I did before.

I realize the time will come, there will be changes, but we'll address those when they come along. That's all you can do."

This conflicted approach was reflected in patients' patterns of information-seeking which revealed mixed attitudes towards future health care needs. Participants accessed information from three main sources, ie, the Internet (50\%), health professionals (36\%), and the ALS Association (36\%). Whilst participants reported appreciation for the information they received from the clinic health professionals and the ALS Association, a small number accepted but chose not to read it.

"When you go to the clinic, the people they are very good with literature ... They all listen to your story and they scurry around and find stuff and give it to you. I must admit we probably don't give it a lot of attention when we come home."

Decision-making was complicated by participants' reluctance to plan for the future, despite the inevitable course of the disease. Coping with the present was preferable to contemplating the future.

\section{Discussion Overview of findings}

This exploratory study offers three levels of factors to account for patient participation in decision-making for management of ALS symptoms and preserving quality of life. The structural factor was the decision-making environment of the specialized ALS multidisciplinary clinics. Interactional factors were patient experiences of ALS, which included patient reactions to the diagnosis, their response to deterioration, and their engagement with the specialized multidisciplinary ALS team. Personal factors were patients' personal philosophies, which comprised their outlook on life, their perception of control, and planning for the future.

Although the participants in this study were actively engaged in multidisciplinary clinic care, they demonstrated paradoxical attitudes towards participation in decisionmaking. On the one hand, patients valued the expert care they received through the specialized multidisciplinary ALS clinics. They appreciated the relationships and trust developed with the clinicians and the information and support the clinic provided. On the other hand, decision-making was a reminder of their inevitable decline, disturbing their sense of well-being and focus on the present. Although patients wished to be well informed about symptoms and progression of ALS, few were comfortable to use this information to make decisions for their compromised life ahead. Patients preferred to wait for their symptoms to deteriorate, rather than plan for their anticipated needs. Patient priorities were to focus on the immediate and maintain their current lifestyle for as long as possible, using the support from specialized clinical ALS services to do so.

\section{Findings in relation to the literature}

Patient responses to a terminal diagnosis such as ALS are personal and complex. ${ }^{35,44,52}$ Attempts to define the personal values $^{53}$ and personality characteristics ${ }^{54,55}$ of ALS patients highlight the individual nature of patients' responses to the disease and to their decision-making. While health practitioners can anticipate aspects of the disease trajectory in their patients, predicting and understanding patient reactions to ALS is not clear-cut. Personality characteristics that promote resilience and assist patients' coping with adverse health conditions need further consideration. Documented challenges to patient participation in ALS services have included inadequate information provision and difficulty accessing services, ${ }^{56,57}$ but this was not the case in our study. Specialized multidisciplinary ALS care was found to facilitate patient engagement in decision-making by providing an optimal environment for information provision, support, and planning. The specialized 
service enabled the development of trusting patient-clinician relationships and provided patients with stability and continuity in their care. The clinics offered a sense of predictability within a continually changing disease context.

Our findings confirm and offer a more nuanced view of previous studies examining perceptions of control. These have indicated two distinct viewpoints of control taken by patients with ALS. ${ }^{29}$ Some studies report an externalized view of control, where ALS is seen to have control over the patients' lives. ${ }^{31,33,58,59}$ Others report internalized control, where patients believe they retain control over their own life. ${ }^{32,54,60}$ Participants in this study expressed a combination of these perceptions. Most acknowledged their lack of control over the disease, reconciled to the fact that health professionals are unable to predict precise individual disease courses and survival times. Nevertheless, patients with ALS also reported a high degree of personal control over their lives. They considered they maintained autonomy, despite the severity of their disease state, but recognized their dependence on family and health professionals. Patients' sense of autonomy regarding decision-making was reinforced by their interactions with the specialized multidisciplinary team.

The patients in our study reported satisfaction with the specialized care they received and the enduring relationships developed with a team of specialist practitioners. Studies of service users recruited from specialized ALS clinic settings have indicated high levels of satisfaction with dedicated multidisciplinary care. ${ }^{32,61}$ However, rigorous assessment of patient satisfaction with specialized multidisciplinary ALS care is yet to be conducted, ${ }^{42}$ and there is a need to explore the benefits to patients of specialized multidisciplinary ALS services in addition to survival times and health outcomes. ${ }^{57}$

\section{Impact of personal factors}

Patient decision-making behavior is strongly influenced by adjustment and coping strategies. A variety of strategies were evident, overlapping with previous research on the coping mechanisms used by ALS patients. ${ }^{35,54,58,60,62,63}$ Participants demonstrated mixed elements of optimism, resilience, denial, avoidance, and delay, frequently expressed as taking "one day at a time" or a "wait and see" approach. ${ }^{30,57,64}$ Avoidance of the future was expressed as not wishing to see others with ALS. ${ }^{52,65}$ Delaying decisions and avoiding ALS information has been viewed as a mechanism for maintaining normality over changed circumstances. ${ }^{59}$ Finding meaning in the present rather than focusing on what had been lost enabled ALS patients to reappraise and reframe their circumstances ${ }^{64}$ and find greater meaning in their family relationships. ${ }^{66,67}$
In contrast with many studies investigating coping mechanisms and quality of life, ,2,63,67-69 $^{3 e l i g i o n}$ and spirituality were not considered important to most participants, and did not influence their decision-making.

There are tensions between patient decision-making behaviors and health professionals' agenda for care. ${ }^{33,34}$ ALS patients and the clinicians who support them show divergent relationships in terms of time, ie, health professionals tend to look to the future, while patients focus on the present. Recognition of this gap will assist health services to provide patient-centered care. The difficulty lies in integrating patient-centeredness with evidence-based care and best practice recommendations. Patients' use of denial as a coping mechanism is problematic for management of ALS symptoms. ${ }^{60,62}$ Denial impacts on participation in decisionmaking when patients disconnect from sources of information on ALS, and disengage from specialized ALS care that is based on anticipation of disease trajectories. ${ }^{31}$

\section{Impact of divergent perspectives}

The disparity between accommodating patients' focus on the present and health professionals' endeavor to provide well-timed care has implications for symptom management, planning of end-of-life care, and the development of clinical guidelines for specialized multidisciplinary clinical ALS services. Delaying decisions impacts on aspects of symptom management that are time-constrained and require forward planning, such as gastrostomy insertion ${ }^{41,70}$ and uptake of mobility and communication equipment. ${ }^{12}$ The "wait and see" approach is contradictory to practice recommendations for anticipatory symptom management, ${ }^{38,41}$ early end-oflife planning, ${ }^{71}$ and timing of palliative care involvement. ${ }^{72}$ Discussions of end-of-life care and transition to palliative care services are delayed, and the efficacy of advance care plans is negated..$^{30}$

\section{Limitations}

We recognize limitations to this study. Generalization of the findings to the broader ALS patient population is restricted by both the number of clinic sites and the sample size. Lack of research on decision-making in ALS patients necessitated the use of an exploratory study. Qualitative methodology enabled indepth examination of patient perspectives, revealing that even when conditions for decision-making were optimal, patients continued to have difficulty engaging in the process. Larger-scale studies may be helpful to measure the specific impact of ALS symptoms, such as cognition, behavior, and mood, on decision-making. 


\section{Conclusion}

This exploratory study offers the position that effective decision-making for symptom management and quality of life in ALS care occurs when the patient's personal values and philosophies are supported by collaborative relationships between the patient and the multidisciplinary ALS team. Patients valued the support provided by the multidisciplinary team; however, their preference for living in the present diverged from the efforts of ALS health professionals to prepare patients and carers for the future. This study of decision-making demonstrates disparity between patient-centered and evidence-based ALS care. The challenge facing health professionals is how to bridge this gap, and best to engage each patient in decisionmaking for symptom management and quality of life.

\section{Acknowledgments}

This research project was funded by the Australian Government Department of Health and Ageing. The authors wish to thank all who took part in this study.

\section{Disclosure}

The authors report no conflicts of interest in this work.

\section{References}

1. Strong MJ, Grace GM, Freedman M, et al. Consensus criteria for the diagnosis of frontotemporal cognitive and behavioural syndromes in amyotrophic lateral sclerosis. Amyotroph Lateral Scler. 2009;10(3): 131-146.

2. Kiernan MC, Vucic S, Cheah BC, et al. Amyotrophic lateral sclerosis. Lancet. 2011;377(9769):942-955.

3. Miller RG, Jackson CE, Kasarskis EJ, et al. Practice parameter update: The care of the patient with amyotrophic lateral sclerosis: multidisciplinary care, symptom management, and cognitive/behavioral impairment (an evidence-based review): report of the Quality Standards Subcommittee of the American Academy of Neurology. Neurology. 2009;73(15):1227-1233.

4. Ganzini L. Artificial nutrition and hydration at the end of life: ethics and evidence. Palliat Support Care. 2006;4(2):135-143.

5. Ganzini L, Goy ER, Dobscha SK. Oregonians' reasons for requesting physician aid in dying. Arch Intern Med. 2009;169(5):489-492.

6. Smyth A, Riedl M, Kimura R, Olick R, Siegler M. End of life decisions in amyotrophic lateral sclerosis: a cross-cultural perspective. J Neurol Sci. 1997;152 Suppl 1:S93-S96.

7. Albert SM, Whitaker A, Rabkin JG, et al. Medical and supportive care among people with ALS in the months before death or tracheostomy. J Pain Symptom Manage. 2009;38(4):546-553.

8. Lemoignan J, Ells C. Amyotrophic lateral sclerosis and assisted ventilation: how patients decide. Palliat Support Care. 2010;8(2): 207-213.

9. McKim DA, King J, Walker K, et al. Formal ventilation patient education for ALS predicts real-life choices. Amyotroph Lateral Scler. 2012;13(1):59-65.

10. Vesey S, Leslie P, Exley C. A pilot study exploring the factors that influence the decision to have PEG feeding in patients with progressive conditions. Dysphagia. 2008;23(3):310-316.

11. Albert SM, Murphy PL, Del Bene ML, Rowland LP. A prospective study of preferences and actual treatment choices in ALS. Neurology. 1999;53(2):278-283.
12. Beukelman D, Fager S, Nordness A. Communication support for people with ALS. Neurol Res Int. 2011;2011:714693.

13. Ward AL, Sanjak M, Duffy K, et al. Power wheelchair prescription, utilization, satisfaction, and cost for patients with amyotrophic lateral sclerosis: preliminary data for evidence-based guidelines. Arch Phys Med Rehabil. 2010;91(2):268-272.

14. Astrow AB, Sood JR, Nolan MT, et al. Decision-making in patients with advanced cancer compared with amyotrophic lateral sclerosis. J Med Ethics. 2008;34(9):664-668.

15. Albert SM, Murphy PL, Del Bene ML, Rowland LP. Prospective study of palliative care in ALS: choice, timing, outcomes. J Neurol Sci. 1999; 169(1-2):108-113.

16. Maessen M, Veldink JH, Onwuteaka-Philipsen BD, et al. Trends and determinants of end-of-life practices in ALS in The Netherlands. Neurology. 2009;73(12):954-961.

17. Munroe CA, Sirdofsky MD, Kuru T, Anderson ED. End-of-life decision making in 42 patients with amyotrophic lateral sclerosis. Respir Care. 2007;52(8):996-999.

18. Foley G. The complexity of care in amyotrophic lateral sclerosis. Amyotroph Lateral Scler. 2011;12(3):160-161.

19. Simonds AK. Living and dying with respiratory failure: facilitating decision making. Chron Respir Dis. 2004;1(1):56-59.

20. Charles C, Gafni A, Whelan T. Decision-making in the physician-patient encounter: revisiting the shared treatment decision-making model. Soc Sci Med. 1999;49(5):651-661.

21. Bélanger E, Rodríguez C, Groleau D. Shared decision-making in palliative care:a systematic mixed studies review using narrative synthesis. Palliat Med. 2010;25(3):242-261.

22. Spathis A, Booth S. End of life care in chronic obstructive pulmonary disease: in search of a good death. Int J Chron Obstruct Pulmon Dis. 2008;3(1):11-29.

23. Moss AH, Casey P, Stocking CB, Roos RP, Brooks BR, Siegler M. Home ventilation for amyotrophic lateral sclerosis patients: outcomes, costs, and patient, family, and physician attitudes. Neurology. 1993 43(2):438-443.

24. Hirano Y, Yamazaki Y. Ethical issues in invasive mechanical ventilation for amyotrophic lateral sclerosis. Nurs Ethics. 2010;17(1):51-63.

25. Nolan MT, Kub J, Hughes MT, et al. Family health care decision making and self-efficacy with patients with ALS at the end of life. Palliat Support Care. 2008;6(3):273-280.

26. Sulmasy DP, Hughes MT, Thompson RE, et al. How would terminally ill patients have others make decisions for them in the event of decisional incapacity? A longitudinal study. J Am Geriatr Soc. 2007;55(12): 1981-1988.

27. Young JM, Marshall CL, Anderson EJ. Amyotrophic lateral sclerosis patients' perspectives on use of mechanical ventilation. Health Soc Work. 1994;19(4):253-260.

28. Whitehead B, O'Brien MR, Jack BA, Mitchell D. Experiences of dying, death and bereavement in motor neurone disease: a qualitative study. Palliat Med. 2012;26(4):368-378.

29. King SJ, Duke MM, O’Connor BA. Living with amyotrophic lateral sclerosis/motor neurone disease (ALS/MND): decision-making about 'ongoing change and adaptation'. J Clin Nurs. 2009;18(5):745-754.

30. Burchardi N, Rauprich O, Hecht M, Beck M, Vollmann J. Discussing living wills. A qualitative study of a German sample of neurologists and ALS patients. J Neurol Sci. 2005;237(1-2):67-74.

31. Hughes RA, Sinha A, Higginson IJ, Down K, Leigh PN. Living with motor neurone disease: lives, experiences of services and suggestions for change. Health Soc Care Community. 2005;13(1):64-74.

32. Foley G, O'Mahony P, Hardiman O. Perceptions of quality of life in people with ALS: effects of coping and health care. Amyotroph Lateral Scler. 2007;8(3):164-169.

33. Brown JB. User, carer and professional experiences of care in motor neurone disease. Primary Health Care Res Devel. 2003;4:207-217.

34. Rodriguez KL, Young AJ. Patients' and healthcare providers' understandings of life-sustaining treatment: are perceptions of goals shared or divergent? Soc Sci Med. 2006;62(1):125-133. 
35. Brown J, Addington-Hall J. How people with motor neurone disease talk about living with their illness: a narrative study. J Adv Nurs. 2008;62(2):200-208.

36. Oliver D. Ventilation in motor neuron disease: difficult decisions in difficult circumstances. Amyotroph Lateral Scler Other Motor Neuron Disord. 2004;5(1):6-8.

37. Hogden A, Greenfield D, Nugus P, Kiernan MC. Engaging patients in decision-making in amyotrophic lateral sclerosis multidisciplinary care: the views of health professionals. Patient Prefer Adherence. 2012;6:691-701.

38. Seeber AA, Hijdra A, Vermeulen M, Willems DL. Discussions about treatment restrictions in chronic neurologic diseases: a structured review. Neurology. 2012;78(8):590-597.

39. Corr B, Frost E, Traynor BJ, Hardiman O. Service provision for patients with ALS/MND: a cost-effective multidisciplinary approach. J Neurol Sci. 1998;160 Suppl 1:S141-S145.

40. Hardiman O. Multidisciplinary care in motor neurone disease. In: Kiernan MC, editor. The Motor Neurone Disease Handbook. Sydney, Australia: MJA Books; 2007.

41. Tsou AY, Karlawish J, McCluskey L, Xie SX, Long JA. Predictors of emergent feeding tubes and tracheostomies in amyotrophic lateral sclerosis (ALS). Amyotroph Lateral Scler. 2012;13(3):318-325.

42. Foley G, Timonen V, Hardiman O. Experience of services as a key outcome in amyotrophic lateral sclerosis (ALS) care: the case for a better understanding of patient experiences. Am J Hosp Palliat Care. 2012;29(5):362-367.

43. Van de Ven AH, Delbecq AL. The nominal group as a research instrument for exploratory health studies. Am J Pub Health. 1972;62(3):337-342.

44. Locock L, Ziebland S, Dumelow C. Biographical disruption, abruption and repair in the context of motor neurone disease. Sociol Health Illn. 2009;31(7):1043-1058.

45. Liamputtong P. Qualitative Research Methods. 3rd ed. Melbourne, Australia: Oxford University Press; 2009.

46. Cedarbaum JM, Stambler N, Malta E, et al. The ALSFRS-R: a revised ALS functional rating scale that incorporates assessments of respiratory function. J Neurol Sci. 1999;169(1-2):13-21.

47. Degner LF, Sloan JA. Decision making during serious illness: what role do patients really want to play? J Clin Epidemiol. 1992;45(9):941-950.

48. Murray E, Pollack L, White M, Lo B. Clinical decision-making: patients' preferences and experiences. Patient Educ Couns. 2007;65(2): 189-196.

49. Murray E, Pollack L, White M, Lo B. Clinical decision-making: physicians' preferences and experiences. BMC Fam Pract. 2007;8:10.

50. Creswell JW. Research Design: Qualitative, Quantitative and Mixed Methods Approaches. 3rd ed. Thousand Oaks, CA: SAGE Publications; 2009.

51. Braun V, Clarke C. Using thematic analysis in psychology. Qual Res Psychol. 2006;3:77-101.

52. Mazanderani F, Locock L, Powell J. Being differently the same: the mediation of identity tensions in the sharing of illness experiences. Soc Sci Med. 2012;74(4):546-553.

53. Fegg MJ, Wasner M, Neudert C, Borasio GD. Personal values and individual quality of life in palliative care patients. J Pain Symptom Manage. 2005;30(2):154-159.

54. Brown WA, Mueller PS. Psychological function in individuals with amyotrophic lateral sclerosis (ALS). Psychosom Med. 1970;32(2): 141-152.

Patient Preference and Adherence

\section{Publish your work in this journal}

Patient Preference and Adherence is an international, peer-reviewed, open access journal focusing on the growing importance of patient preference and adherence throughout the therapeutic continuum. Patient satisfaction, acceptability, quality of life, compliance, persistence and their role in developing new therapeutic modalities and compounds to
55. Krampe H, Bartels C, Victorson D, et al. The influence of personality factors on disease progression and health-related quality of life in people with ALS. Amyotroph Lateral Scler. 2008;9(2):99-107.

56. O'Brien MR, Whitehead B, Jack BA, Mitchell JD. From symptom onset to a diagnosis of amyotrophic lateral sclerosis/motor neuron disease (ALS/MND): experiences of people with ALS/MND and family carers a qualitative study. Amyotroph Lateral Scler. 2011;12(2):97-104.

57. Foley G, Timonen V, Hardiman O. Patients' perceptions of services and preferences for care in amyotrophic lateral sclerosis: a review. Amyotroph Lateral Scler. 2012;13(1):11-24.

58. Houpt JL, Gould BS, Norris FH Jr. Psychological characteristics of patients with amyotrophic lateral sclerosis (ALS). Psychosom Med. 1977;39(5):299-303.

59. Hugel H, Grundy N, Rigby S, Young CA. How does current care practice influence the experience of a new diagnosis of motor neuron disease? A qualitative study of current guidelines-based practice. Amyotroph Lateral Scler. 2006;7(3):161-166.

60. Hogg KE, Goldstein LH, Leigh PN. The psychological impact of motor neurone disease. Psychol Med. 1994;24(3):625-632.

61. McCabe MP, Roberts C, Firth L. Satisfaction with services among people with progressive neurological illnesses and their carers in Australia. Nurs Health Sci. 2008;10(3):209-215.

62. Matuz T, Birbaumer N, Hautzinger M, Kübler A. Coping with amyotrophic lateral sclerosis: an integrative view. J Neurol Neurosurg Psychiatry. 2010;81(8):893-898.

63. Montel S, Albertini L, Spitz E. Coping strategies as related to medical and demographic data in amyotrophic lateral sclerosis. Acta Neurol Scand. 2012;125(2):136-141.

64. Young JM, McNicoll P. Against all odds: positive life experiences of people with advanced amyotrophic lateral sclerosis. Health Soc Work. 1998;23(1):35-43.

65. Locock L, Brown JB. 'All in the same boat'? Patient and carer attitudes to peer support and social comparison in motor neurone disease (MND). Soc Sci Med. 2010;71(8):1498-1505.

66. Mock S, Boerner K. Sense making and benefit finding among patients with amyotrophic lateral sclerosis and their primary caregivers. J Health Psychol. 2010;15(1):115-121.

67. Nelson ND, Trail M, Van JN, Appel SH, Lai EC. Quality of life in patients with amyotrophic lateral sclerosis: perceptions, coping resources, and illness characteristics. J Palliat Med. 2003;6(3):417-424.

68. Johnson JO, Sulmasy DP, Nolan MT. Patients' experiences of being a burden on family in terminal Illness. J Hosp Palliat Nurs. 2007;9(5): 264-269.

69. Murphy PL, Albert SM, Weber CM, Del Bene ML, Rowland LP. Impact of spirituality and religiousness on outcomes in patients with ALS. Neurology. 2000;55(10):1581-1584.

70. Beggs K, Choi M, Travlos A. Assessing and predicting successful tube placement outcomes in ALS patients. Amyotroph Lateral Scler. 2010;11(1-2):203-206.

71. Mitsumoto H, Bromberg M, Johnston W, et al. Promoting excellence in end-of-life care in ALS. Amyotroph Lateral Scler Other Motor Neuron Disord. 2005;6(3):145-154.

72. Bede $\mathrm{P}$, Oliver D, Stodart J, et al. Palliative care in amyotrophic lateral sclerosis: a review of current international guidelines and initiatives. J Neurol Neurosurg Psychiatry. 2011;82(4):413-418.

optimize clinical outcomes for existing disease states are major areas of interest. This journal has been accepted for indexing on PubMed Central The manuscript management system is completely online and includes a very quick and fair peer-review system. Visit http://www.dovepress.com/ testimonials.php to read real quotes from published authors. 